Michael C. Ellis · Angela H. Hetisimer · David A. Ruddy

Sherry L. Hansen • Gregory S. Kronmal

Erin McClelland · Leah Quintana - Dennis T. Drayna

Michael S. Aldrich · Emmanuel Mignot

\title{
HLA class II haplotype and sequence analysis support a role for $D Q$ in narcolepsy
}

Received: 18 March 1997 / Revised: 23 April 1997

\begin{abstract}
A systematic haplotype and sequencing analysis of the $H L A$-DR and $-D Q$ region in patients with narcolepsy was performed. Five new $(\mathrm{CA})_{\mathrm{n}}$ microsatellite markers were generated and positioned on the physical map across the HLA-DQB1-DQA1-DRB1 interval. Haplotypes for these new markers and the three HLA loci were established using somatic cell hybrids generated from patients. A fourmarker haplotype surrounding the $D Q B 1 * 0602$ gene was found in all narcolepsy patients, and was identical to haplotypes observed on random chromosomes harboring the $D Q B 1 * 0602$ allele. Eighty-six kilobases of contiguous genomic sequence across the region did not reveal new genes, and analysis of this sequence for single nucleotide polymorphisms did not reveal sequence variation among $D Q B 1 * 0602$ chromosomes. These results are consistent with other studies, suggesting that the HLA-DQ genes themselves are among the predisposing factors in narcolepsy.
\end{abstract}

\section{Introduction}

Narcolepsy is a debilitating, lifelong sleep disorder that typically arises during early adulthood (Aldrich 1993). The

M. C. Ellis • A. H. Hetisimer ${ }^{1}$ - D. A. Ruddy - S. L. Hansen

G. S. Kronmal • E. McClelland - Leah Quintana - D. T. Drayna ${ }^{2}$

Mercator Genetics, Inc., 4040 Campbell Ave., Menlo Park, CA 94025, USA

\section{S. Aldrich}

Department of Neurology, Sleep Disorders Center,

University of Michigan Medical Center, Ann Arbor, MI 48109, USA

E. Mignot $(\bullet)$

Stanford Center for Narcolepsy Research, Stanford University School of Medicine, Palo Alto, CA 94304, USA

Present addresses:

${ }^{1}$ Internal Medicine-Rheumatology, University of Michigan, Ann Arbor, MI 48109, USA

2National Human Genome Research Institute,

National Institutes of Health, Bethesda, MD 20892, USA abnormal patterns of REM sleep and associated clinical features observed in narcoleptics suggest that the disease affects fundamental mechanisms of sleep regulation (Aldrich 1993). The measured frequency of the disease ranges from 1 in 4000 in North American and European Caucasians to 1 in 600 in Japan (Mignot 1997). There is no cure for the disease, and current treatments with amphetamines and antidepressants are purely symptomatic and largely unsatisfactory (Nishino and Mignot 1997).

The pathophysiological mechanisms underlying narcolepsy are unknown. Neurochemical studies suggest abnormal monoaminergic and cholinergic transmission in both humans and in a dog model of the disorder (Aldrich et al. 1994; Nishino and Mignot 1997). There have been no clear demonstrations of tissue damage associated with the disease in humans (Erlich and Itabashi 1986), but recent results in the dog model have shown increased microglial major histocompatibility complex class II expression in the white matter and neuronal degeneration in the amygdala and in the basal forebrain around the time of disease onset (Siegel et al. 1995; Tafti et al. 1996).

A clue to the molecular basis of narcolepsy has come from genetic association studies. Since the early 1980s, narcolepsy has been known to be strongly associated with specific alleles of genes in the HLA class II region on chromsome 6p21 (Juji et al. 1984). This was first observed with protein-based marker systems (Andreas-Zietz et al. 1987; Billiard et al. 1986; Juji et al. 1984; Mueller-Eckhardt et al. 1986; Neely et al. 1986; Poirier et al. 1986), and subsequently with more specific DNA-based systems (Mignot et al.1994, 1997; Rogers et al. 1997). Recent studies have demonstrated that $85 \%-100 \%$ of Causasian and Japanese patients with narcolepsy/cataplexy are positive for the $H L A$ class II alleles $D Q B 1 * 0602, D Q A 1 * 0102$, and $D R B 1 * 1501$ (Lin et al.1992; Mignot et al. 1994; Rogers et al. 1997). Similarly, American Black patients exhibit a $>90 \%$ frequency of the $D Q B 1 * 0602 / D Q A 1 * 0102$, but exhibit reduced association at the $D R B 1$ locus (Mignot et al. 1994, 1997; Rogers et al. 1997). These results suggest the presence of a narcolepsy susceptibility factor in the immediate $D Q B 1 / D Q A 1$ region. Sequencing of the $D Q$ and 
Table 1 Primer sequences for markers developed in this study. Markers are listed by GDB-assigned D-segment numbers for microsatellite markers, and by STS name for other markers. Size ranges are given for microsatellites. Alleles are listed as size variations for microsatellites, or DGGE/RFLP polymorphisms detected in STSs 2E3, 2D7, 2C10, and 9-10 (see Materials and methods). GDB accession numbers are listed in the last column

\begin{tabular}{|c|c|c|c|c|}
\hline Locus/STS name & Size (bp) & PCR primers & Alleles & GDB ID \\
\hline D6S2445 & $162-198$ & $\begin{array}{l}\text { AATATGATGGAAGAAGTAATCCAG } \\
\text { GGATTACAGGTATAAGCCATTG }\end{array}$ & 6 & GDB : 5886533 \\
\hline D6S2444 & $142-158$ & $\begin{array}{l}\text { GAGCCAAGAACCCAGCATTC } \\
\text { GGAAGGATTCTAAATAGGGGAG }\end{array}$ & 8 & GDB : 5886535 \\
\hline D6S2443 & $169-203$ & $\begin{array}{l}\text { CCATACCAAAGTAAAACCCAG } \\
\text { GAGGATGAAGGGAAATTAGAG }\end{array}$ & 9 & GDB : 5886534 \\
\hline D6S2447 & $178-200$ & $\begin{array}{l}\text { TTGAGAGGTGTGCATGTTAC } \\
\text { GCATTTCTCTTCCTTATCACTTC }\end{array}$ & 9 & GDB : 5886537 \\
\hline D6S2446 & $168-200$ & $\begin{array}{l}\text { GAGAATCCAGCATATTGGAG } \\
\text { CACTATCATTAAATTTGCTTTCCAC }\end{array}$ & 13 & GDB : 5886536 \\
\hline D6F374S1 & $\sim 190$ & $\begin{array}{l}\text { CGGGATTGAGAGGATTCTAAATG } \\
\text { GTGAGAGCTTCACAGTGCAG }\end{array}$ & Many & GDB : 5886538 \\
\hline $2 \mathrm{E} 3$ & 246 & $\begin{array}{l}\text { GTAGGGAGTTGTAATAGGTTTG } \\
\text { TTTGGTGGGTCATTATGTATTATC }\end{array}$ & 3 & GDB : 5886539 \\
\hline 2D7 & 437 & $\begin{array}{l}\text { GGAAAGGAATGTTATGCTCTG } \\
\text { AGGAGTGGGGTGTTATTG }\end{array}$ & 2 & GDB : 5886540 \\
\hline $2 \mathrm{C} 10$ & 3496 & $\begin{array}{l}\text { GAGGTGTGTTGGAAAGAG } \\
\text { GTAGGATGGGATTGGATTG }\end{array}$ & 3 & GDB : 5886542 \\
\hline $9-10$ & 593 & $\begin{array}{l}\text { TGAGCACAGTGGATTGAG } \\
\text { TGGTAGTTGTCAGGAAGG }\end{array}$ & 3 & GDB : 5886541 \\
\hline
\end{tabular}

DRB1 genes from narcoleptic and control individuals has revealed no polymorphisms that correlate with the disease (Lock et al. 1988; Mignot et al. 1994; Uryu et al. 1989). Since $D Q B 1 * 0602 / D Q A 1 * 0102$ is a very common haplotype in all populations (Fernandez-Vina et al. 1991; Yasunaga et al. 1996), the predictive value of these markers with respect to disease is low.

In the current study, we took a systematic approach to identify genetic variation across the narcolepsy-associated $H L A$ class II region. By developing and mapping novel polymorphic markers in conjunction with existing $H L A$ markers, we investigated whether a $D Q B 1 * 0602$ haplotype of higher predictive value can be distinguished in narcoleptic versus control subjects.

\section{Materials and methods}

Human subjects and cell line subjects were 23 patients with narcolepsy-cataplexy, identified from the University of Michigan Sleep Disorders Center database. All subjects had definite cataplexy characterized by brief episodes of bilateral muscle weakness, which were triggered by emotion and were not associated with loss of consciousness. Sixteen had been tested with a Multiple Sleep Latency Test (MSLT), and the other seven subjects were all over the age of 50 with long histories of unambiguous narcolepsy/cataplexy. Fourteen of the 16 had MSLT results typical for narcolepsy (mean sleep latency of less than 5 minutes and two or more Sleep Onset REM periods). After informed consent, $10-35 \mathrm{ml}$ whole blood was obtained by venipuncture. Genomic DNA from blood was prepared as previously described (Wolff et al. 1992). Immortalized cell lines were established using standard procedures and hybrid cell lines containing chromosome 6 were produced as previously described (Jackson 1994). Cell lines containing individual homologues of chromosome 6 were selected based on their containing only one allele of a genetic marker on chromosome 6 known to be heterozygous in that individual. Random human samples were from two sources. In cases where the phase of markers was desired, genomic DNA from 26 individuals of the grandparental generation of the CEPH/Utah families were used (Cor- iell Cell Repositories, Camden, NJ). Additional Caucasian random individuals were sampled from Mercator Genetics, Inc.

\section{HLA typing}

$H L A$ class II typing was performed using available typing systems for HLA-DQB1, DQA1, and DRBI (Olerup and Zetterquist 1992; Olerup et al. 1993), which are based on polymerase chain reaction (PCR) assays with allele-specific oligonucleotide primers (Dynal Inc., Lake Success, NY), according to the manufacturer's instructions. Allele frequencies were compared with published population studies Begorich et al. 1992; Fernandez-Vina et al. 1991).

\section{Genomic clones}

DNA substrates for the development of microsatellite markers were the yeast artificial chromosomes (YACs) A148A7 and B1D12, which were previously shown to span the class II region (Kozono et al. 1991). These YACs were sized using Bio Rad (Hercules, CA) CHEF gels (Chu et al. 1986) and found to be 360 kilobases (kb) (A148A7) and $375 \mathrm{~kb}$ (B1D12) in size. Additional YACs spanning the class II region (clones 410A3, 283E9, 405C3, 98E6, and 129B9) were from the CEPH map of the region (Abderrahim et al. 1994). P1 clones $\mathrm{p} 312 \mathrm{~g} 9$ and p797a11 were isolated by virtue of their containing a sequence-tagged site (STS; primers GH26 and GH27) in the DQA1 gene (Scharf et al. 1986), and were obtained from the screening service at Genome Systems Inc. (St. Louis, MO).

\section{Microsatellite marker development and genotyping}

DNA from YACs A148A7 and B1D12 was used to construct a cosmid library in the modified sCos vector sCos-dRI (Gillett et al. 1996); a gift of J. Yu, University of Washington. Eco RI fragments containing polymorphic $(\mathrm{CA})_{\mathrm{n}}$ repeats were identified using standard methods (Litt and Browne 1994; Weber 1990), and then subcloned and sequenced on both strands. PCR primers flanking the $(\mathrm{CA})_{\mathrm{n}}$ repeat were designed using the program OSP (Hillier and Green 1991). The marker D6S273 was from Research Genetics (Huntsville, AL), and maps to the $H L A$ class III region near the complement factor $B$ and $C 4$ genes, based on reference to the MIT/Whitehead database (Hudson et al. 1995). All markers were assayed according to standard conditions 
A
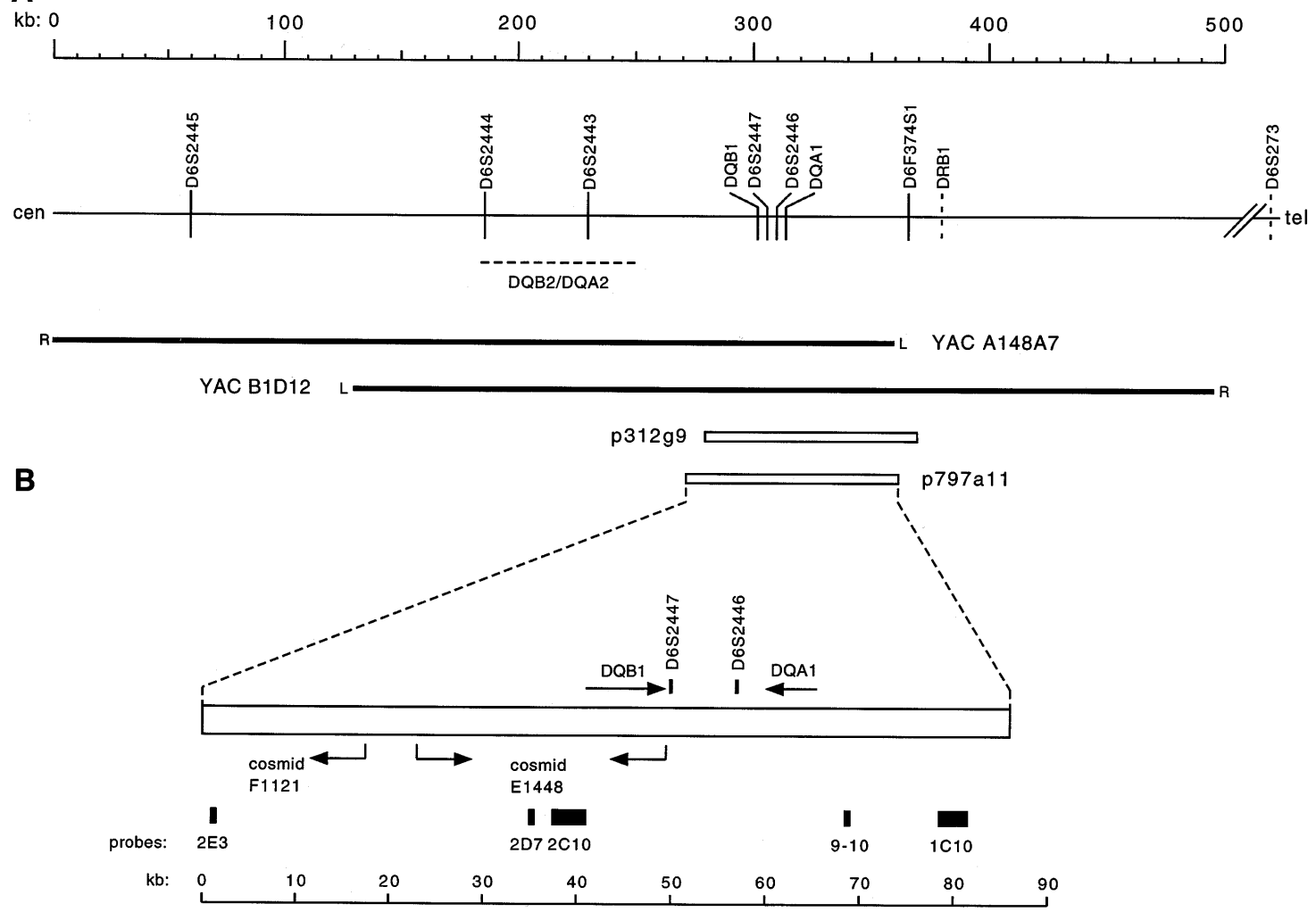

(Weber and May 1989). Sequence analysis and position of $D 6 F 374 S 1$ indicated that it derived from the DRB1/DRB6 pseudogene region. Data from this marker was not used for scoring, as it amplified multiply duplicated sequences from this region (data not shown). Oligonucleotide sequences for markers developed in this study are shown in Table 1. Additional information for these markers such as allele frequencies and PCR conditions have been deposited with GDB.

\section{Marker mapping}

Physical map positions of new genetic markers were established using RecA-assisted restriction endonuclease (RARE) cleavage (Ferrin and Camerini-Otero 1991). Eco RI subclones containing (CA)n repeats were sequenced at the insert/vector junction to identify the genomic sequence adjacent to the Eco RI site. Oligonucleotides from this sequence were used in RARE cleavage experiments as described (Gnirke et al. 1994; Iadonato and Gnirke 1994). Eco RI sites adjacent to $(\mathrm{CA})_{\mathrm{n}}$ repeat markers were initially positioned on the YACs A148A7 and B1D12, and were confirmed on a second set of YACs that also span the class II region (410A3, 283E9, 405C3, 98E6, 129B9).

\section{Genomic sequencing and computer analysis}

The P1 clone p797a11 was used as a substrate for genomic sequencing, which was performed as described (Ruddy et al. 1997). Finished sequence was analyzed using the gene prediction program GRAIL (Uberbacher et al. 1996) and by searching the sequence against GenBank using BLAST (Altschul et al. 1990). The $86 \mathrm{~kb}$ sequence of p797a11 has been deposited in GenBank (accession number U92032). Based on GenBank comparisons, the HLA type of p797a11 is most likely $D Q B 1 * 0201, D Q A 1 * 0501$.

\section{Polymorphism analysis}

STSs designed from the p797a11 sequence were amplified from genomic samples using either standard PCR (probes 2E3, 2D7, 9-10)
Fig. 1 A Map of the $H L A$ class II region and clones used in this study. Scale bar in kb is shown at the top of the Figure. The second line indicates the positions of loci used as genetic markers in this study that were determined by RARE cleavage, indicated as vertical lines. Probes adjacent to markers D6S2447 and D6S2446 gave two positions when used in RARE cleavage experiments due to sequence similarity to loci in the $D Q B 2$ region. The actual positions of these markers were confirmed through genomic sequencing. The position of D6F374S1 as determined by RARE cleavage and analysis of its sequence (data not shown) indicate that it derives from the DRB1/DRB6 pseudogene region. The positions of $D Q B 2, D Q A 2, D R B 1$, and $D 6 S 273$ are based on references to other maps (Hudson et al. 1995; Kozono et al. 1991) and are thus approximate, and represented by dashed lines. The sizes and approximate endpoints of the indicated YAC (heavy lines) and P1 (open bars) clones are shown. The left and right ends of the YAC clones are indicated by " $L$ " and " $R$ ", respectively. B Schematic representation of the sequence of p797a11. The $86 \mathrm{~kb}$ of genomic sequence is represented by the open bar. The positions of the $D Q B 1$ and $D Q A 1$ genes and the size and direction of transcription are represented above the bar, as are the positions of D6S2447 and D6S2446. The positions at which the genomic sequence of p797a11 overlaps sequences from cosmids F1121 and E1448 (Sanger Centre, $\mathrm{UK})$ are indicated. The positions of the probes $2 \mathrm{E} 3,9-10,2 \mathrm{D} 7,2 \mathrm{C} 10$, and $1 \mathrm{C} 10$ that were used as assays for sequence polymorphism are indicated below the bar (see Materials and methods). With the exception of probe $1 \mathrm{C} 10$, which detected an Msp I polymorphism in the $D Q B 1 * 0602$ chromosome from Black patient NY14 that was not detected among the other $D Q B 1 * 0602$ chromsomes used in this study, all $D Q B 1 * 0602$ chromosomes were identical, whether from narcoleptic or random subjects

or long-range PCR (probe 2C10), using the TaKaRa LA PCR kit (PanVera Corp., Madison, WI) according to the manufacturer's instructions. Sequences of primers for these STSs are shown in Table 1. Standard size STSs were analyzed for sequence polymorphism using denaturing gradient gel electrophoresis (DGGE), using gel systems and temperature control tanks from the C.B.S. Scientific Company, Inc. 
Table 2 Genotyping data from 23 narcolepsy patients. Genotyping information is listed for the 23 narcolepsy patients used in this study. Numbers denote allele sizes in bp, except for $D Q B 1, D Q A 1$, and $D R B 1$, where alleles are denoted according to the standard nomenclature for each respective typing system. Patients for which somatic cell hybrid lines were established for each homologue of chromosome 6 are indicated with a $(*)$, and the haplotype from the individual homologue is listed. Markers which define the four-marker haplotype in common among all patients are boxed

\begin{tabular}{|c|c|c|c|c|c|c|c|c|c|c|}
\hline Patient & Race & D6S2445 & D6S2444 & D6S443 & DQB1 & D6S2447 & D6S2446 & DQA1 & DRB1 & D6S273 \\
\hline NY1 & $\mathrm{C}$ & $180 / 164$ & $148 / 144$ & $199 / 169$ & $0501 / 0602$ & $182 / 182$ & $186 / 184$ & 0101/0102 & $01 / 1501$ & $136 / 134$ \\
\hline NY2 & $\mathrm{C}$ & $164 / 164$ & $152 / 144$ & $197 / 169$ & 03/0602 & $198 / 182$ & $184 / 172$ & 04/0102 & $11 / 1501$ & $136 / 134$ \\
\hline NY3 & $\mathrm{C}$ & $164 / 164$ & $152 / 144$ & $197 / 169$ & 0402/0602 & $190 / 182$ & $184 / 182$ & 04/0102 & 08/1501 & $136 / 132$ \\
\hline NY4 & $\mathrm{C}$ & $164 / 164$ & $152 / 148$ & $201 / 197$ & $03 / 0602$ & $190 / 182$ & $184 / 178$ & $03 / 0102$ & $04 / 1501$ & $136 / 132$ \\
\hline NY5 & $\mathrm{C}$ & $164 / 162$ & $144 / 144$ & $179 / 169$ & $03 / 0602$ & $196 / 182$ & $184 / 170$ & 04/0102 & $12 / 1501$ & $136 / 134$ \\
\hline \multirow[t]{2}{*}{ *NY6 } & B & 164 & 142 & 179 & 03 & 196 & 170 & 04 & 11 & 136 \\
\hline & & 164 & 144 & 169 & 0602 & 182 & 184 & 0102 & 11 & 132 \\
\hline *NY7 & & 162 & 152 & 171 & 02 & 178 & 188 & 04 & 03 & 140 \\
\hline \multirow[t]{2}{*}{ *NY8 } & $\mathrm{C}$ & 162 & 144 & 171 & 03 & 196 & 178 & 0302 & 04 & 134 \\
\hline & & 162 & 152 & 197 & 0602 & 182 & 184 & 0102 & 1501 & 132 \\
\hline NY9 & $\mathrm{C}$ & $164 / 162$ & $152 / 144$ & $197 / 169$ & $03 / 0602$ & $198 / 182$ & $184 / 172$ & 04/0102 & $11 / 1501$ & $136 / 134$ \\
\hline \multirow{2}{*}{ *NY10 } & $\mathrm{C}$ & 162 & 144 & 169 & 0602 & 182 & 184 & 0102 & 1501 & 136 \\
\hline & & 162 & 144 & 169 & 03 & 198 & 202 & 0201 & 07 & 136 \\
\hline NY11 & $\mathrm{C}$ & $164 / 162$ & $152 / 152$ & $197 / 171$ & $02 / 0602$ & $182 / 178$ & $188 / 184$ & $0501 / 0102$ & $0301 / 1501$ & $140 / 136$ \\
\hline *NY12 & $\mathrm{C}$ & 164 & 152 & 199 & 0602 & 182 & 184 & 0102 & 1501 & 136 \\
\hline \multirow[t]{2}{*}{ *NY13 } & $\mathrm{C}$ & 164 & 158 & 179 & 02 & 192 & 204 & 0201 & 07 & 130 \\
\hline & & 164 & 152 & 197 & 0602 & 182 & 184 & 0102 & 1501 & 136 \\
\hline \multirow[t]{2}{*}{ *NY14 } & B & 194 & 144 & 179 & 0602 & 182 & 184 & 0102 & 11 & 136 \\
\hline & & 164 & 144 & 169 & 0501 & 182 & 182 & 0101 & 1001 & 132 \\
\hline \multirow[t]{2}{*}{ *NY15 } & $\mathrm{C}$ & 164 & 152 & 197 & 0602 & 182 & 184 & 0102 & 1501 & 136 \\
\hline & & 164 & 152 & 195 & 0602 & 182 & 184 & 0102 & 1501 & 140 \\
\hline \multirow[t]{2}{*}{ *NY16 } & $\mathrm{C}$ & 164 & 152 & 197 & 0602 & 182 & 182 & 0102 & 1501 & 136 \\
\hline & & 162 & 144 & 169 & 0602 & 182 & 184 & 0102 & 1501 & 136 \\
\hline \multirow[t]{2}{*}{ *NY17 } & $\mathrm{C}$ & 164 & 152 & 197 & 0602 & 182 & 184 & 0102 & 1501 & 136 \\
\hline & & 164 & 142 & 169 & 0501 & 182 & 186 & 0101 & 01 & 134 \\
\hline NY18 & $\mathrm{C}$ & $164 / 164$ & $152 / 152$ & $197 / 197$ & $0602 / 0602$ & $182 / 182$ & $184 / 184$ & 0104/0102 & $1501 / 1501$ & $136 / 136$ \\
\hline \multirow[t]{2}{*}{ *NY19 } & $\mathrm{C}$ & 162 & 144 & 169 & 0602 & 182 & 184 & 0102 & 1501 & 136 \\
\hline & & 164 & 144 & 169 & 0602 & 182 & 184 & 0102 & 1501 & 136 \\
\hline NY20 & $\mathrm{C}$ & $164 / 162$ & $152 / 144$ & $197 / 169$ & 03/0602 & $198 / 182$ & $184 / 172$ & 0501/0102 & $11 / 1501$ & $136 / 134$ \\
\hline NY21 & $\mathrm{C}$ & $162 / 162$ & $152 / 144$ & $171 / 169$ & $02 / 0602$ & $182 / 178$ & $188 / 184$ & $0501 / 0102$ & $0301 / 1501$ & $140 / 136$ \\
\hline NY22 & $\mathrm{C}$ & $180 / 162$ & $148 / 144$ & $201 / 169$ & $03 / 0602$ & $190 / 182$ & $184 / 178$ & $0301 / 0102$ & $04 / 1501$ & $136 / 134$ \\
\hline *NY23 & B & 190 & 144 & 179 & 03 & 196 & 170 & 0501 & 11 & 134 \\
\hline
\end{tabular}

(Del Mar, CA), and techniques as described (Myers et al. 1988). Dde I and Alu I polymorphisms were detected in the 2C10 STS on standard agarose or polyacrylamide gels. The $3 \mathrm{~kb}$ clone $1 \mathrm{C} 10$ from p797a11 was used as a probe on Southern blots of human genomic DNA to detect Msp I polymorphisms according to standard techniques.

\section{Results}

Five microsatellite markers developed and mapped in the HLA class II region

Our objective in the current study was to identify genetic variation across the entire HLA class II region and to measure allelic associations with narcolepsy. As a first step, we set out to develop polymorphic markers across the region using two well-characterized YACs (clones A148A7 and B1D12) that span the region, as shown in Fig. 1 (Kozono et al. 1991). We chose to develop simple tandem repeat polymorphisms (STRPs) of the (CA) n dinucleotide class, as they are among the most common form of polymorphic repeat in the human genome (Beckmann and Weber 1992). Using YACs A148A7 and B1D12 as starting material, six independent $(\mathrm{CA})_{\mathrm{n}}$ markers were isolated and characterized (see Materials and methods). The physical positions of these markers were determined using Rec-Aassisted restriction endonuclease cleavage, or RARE cleavage, (Ferrin and Camerini-Otero 1991), a technique for mapping individual Eco RI sites relative to the end of a YAC (Gnirke et al. 1994; Iadonato and Gnirke 1994). The six $(\mathrm{CA})_{n}$ markers were positioned over a region extending approximately $300 \mathrm{~kb}$ centromeric from the $D R B 1$ region (Fig. 1). All distances and locations were confirmed by performing RARE cleavage on a second set of YACs from the class II region isolated from the CEPH library, an independent source of YACs (Abderrahim et al. 1994).

These markers were tested on 23 narcolepsy/cataplexy patients and 26 random individuals of Caucasian descent in order to determine allele frequencies. Genotyping data from D6F374S1 could not be scored, due to apparent amplification of multiply duplicated sequences and was not used for further analysis. In total, scorable $(\mathrm{CA})_{\mathrm{n}}$ markers were developed at five loci through the class II region (Fig. 1). All five markers displayed multiple alleles (Table 1), and were highly polymorphic (heterozygosity $>65 \%$ ). Notably, all 23 narcolepsy patients carried allele 182 of marker 
Table 3 Haplotypes of $D Q B 1^{*} 0602$ chromosomes from narcoleptic and random individuals. Alleles are listed as in Table 2. Haplotypes were established from narcolepsy patient hybrid cell lines or from phased CEPH individuals. The four-marker haplotype associated with
$D Q B 1^{*} 0602$ is underlined. Haplotypes at flanking markers were not conserved. One homologue from patient NY16 in which allele 182 of marker $D 6 S 2446$ presumably arose by mutation is indicated by $\left(^{*}\right)$

\begin{tabular}{|c|c|c|c|c|c|c|c|c|c|}
\hline & Number & D6S2444 & D6S2443 & $D Q B 1$ & D6S2447 & D6S2446 & $D Q A 1$ & $D R B 1$ & D6S273 \\
\hline \multirow[t]{2}{*}{ Patient } & 15 & Variablea & Variablea & $\underline{0602}$ & 182 & 184 & $\underline{0102}$ & Variablea & Variablea \\
\hline & 1 & 152 & 197 & 0602 & 182 & $182^{*}$ & 0102 & 1501 & 136 \\
\hline \multirow[t]{2}{*}{ Random } & 3 & 152 & 197 & $\overline{0602}$ & 182 & 184 & 0102 & ND & ND \\
\hline & 2 & 144 & 169 & $\overline{0602}$ & 182 & $\overline{184}$ & $\overline{0102}$ & ND & ND \\
\hline
\end{tabular}

a See Table 2

ND: not determined

D6S2447 and allele 184 of marker D6S2446 (see below). During subsequent analysis, we discovered that markers D6S2447 and D6S2446 are identical to previously characterized DQCAR, and DQCARII markers, respectively (Macaubas et al. 1995; Mignot et al. 1995a, 1997). The D6S2447 PCR product is 79 base pairs (bp) longer than reported $D Q C A R$ alleles, whereas D6S2446 alleles are $16 \mathrm{bp}$ shorter than DQCARII alleles. The pattern of allelic association of D6S2447 and D6S2446 with HLA DQ and DR observed in this study is identical to that reported with $D Q C A R$ and DQCARII (data not shown).

Narcoleptics share a common haplotype around the $D Q B 1 * 0602$ gene that is indistinguishable from control haplotypes

To determine the genetic variation present at the class II loci, the 23 narcoleptic patients were typed at the three HLA genes $D Q B 1, D Q A 1$, and $D R B 1$ using available PCR-SSP systems. Results are shown in Table 2. Consistent with previously reported studies, all Caucasian patients carried $D Q B 1 * 0602$ and $D Q A 1 * 0102$ in association with $D R B 1 * 1501$. All Black patients were also $D Q B 1 * 0602$ and $D Q A 1 * 0102$ but carried more variable $D R B 1$ types (i.e., $D R B 1 * 11$ and $D R B 1 * 1503$ ).

To establish the phase for all the markers used in this study, somatic cell hybrids carrying single homologues of chromosome 6 were established for 12 of the narcolepsy patients used in this study, which allows the unambiguous assignment of alleles to a specific haplotype (Table 2). This analysis revealed that allele 182 of marker D6S2447 and the 184 allele of marker D6S2446 were in nearly complete linkage disequilibrium with the $D Q B 1 * 0602 / D Q A 1 * 0102$ narcolepsy susceptibility haplotype. Overall, the 0602/182/ 184/0102 haplotype was observed on 15 separated chromosomes derived from 12 patients, and inferred in the remaining 11 patients (Table 2). One chromosome (from patient NY16) carried D6S2446 allele 182 on an otherwise identical $D Q B 1 * 0602$ chromosome (Table 3), presumably a rare allele that arose through mutation at the $(\mathrm{CA})_{\mathrm{n}}$ locus. At markers flanking the immediate $D Q$ region (D6S2445, D6S2444, and D6S2443 centromeric, and DRB1 and D6S273 telomeric), haplotypes were not conserved (Table 2).

To compare the haplotypes observed in narcolepsy patients with those from random individuals, we identified individuals with a $D Q B 1 * 0602$ allele from the CEPH/Utah families. Because these individuals are in families, one can follow the inheritance pattern of the individual chromsomes to establish phase for markers. The results of this analysis are shown in Table 3. The HLA/microsatellite haplotypes observed in these individuals do not differ from those observed in narcolepsy patients. These results suggest that the pattern of linkage disequilibrium is the same in narcoleptics and controls with $D Q B 1 * 0602$, and thus at this level of resolution there does not appear to be a narcolepsyspecific "subhaplotype" among DQB1*0602 chromosomes.

Sequencing and polymorphism studies did not reveal narcolepsy-specific sequence variation or other genes in the $D Q$ region

To approach the identification of additional polymorphism that is not reflected in the $H L A /$ microsatellite haplotype, we determined the complete sequence of a P1 clone that spans the $D Q$ region and used this as a tool to develop assays for sequence polymorphism (Fig. 1). This P1 clone extends from $\sim 40 \mathrm{~kb}$ centromeric of $D Q B 1$ to $\sim 40 \mathrm{~kb}$ telomeric of $D Q A 1$. Analysis of the $86 \mathrm{~kb}$ of complete genomic sequence by BLAST searches and the gene identification program GRAIL identified the genes for $D Q B 1$ and $D Q A 1$, but gave no evidence for other genes in the region (Fig. 1). Sequence variation was assayed either by testing STSs from multiple individuals on gel based systems to detect polymorphism (see Materials and methods), or by detection of restriction fragment-length polymorphisms (RFLP) on Southern blots of genomic DNA from multiple individuals. In total, these techniques were used to assay $7.8 \mathrm{~kb}$ of genomic sequence. Polymorphisms were detected in all five probes among various haplotypes (Table 1), and four of the five showed no polymorphism among $D Q B 1 * 0602$ chromosomes (Fig. 1). Probe 1C10, which detected an Msp I RFLP between $D Q B 1 * 0602$ chromosomes from Caucasians (all $D Q B 1 * 0602 / D R B 1 * 1501$-positive) and Black patient NY14 (DQB1*0602/DR11-positive), may define a telomeric boundary of the region of identity. Although this analysis confirms the existence of a high degree of polymorphism among various HLA haplotypes, it does not provide evidence for sequence variation among $D Q B 1 * 0602$ chromosomes in the immediate $D Q$ region. 


\section{Discussion}

In this study, we identified a four-marker haplotype in the $D Q$ region, which is strongly associated with narcolepsy, and confirmed that the disease susceptibility region does not extend to DRB1 (Mignot et al. 1994, 1997; Neely et al. 1987; Rogers et al. 1997), or to $D Q A 2 / D Q B 2$ (Honda and Matsuki 1990; Mignot et al. 1997). This $D Q B 1 * 0602$ associated haplotype is indistinguishable from the $D Q B 1 * 0602$ haplotypes observed on random control chromosomes, thus suggesting that a narcolepsy-specific subhaplotype does not exist among $D Q B 1 * 0602$ chromosomes. It remains formally possible that thus far undetected polymorphism among $D Q B 1 * 0602$ chromosomes is involved in narcolepsy, but the bulk of the genetic evidence accumulated to date argues against this possibility. In family studies, $D Q B 1 * 0602$-positive narcoleptic patients can inherit the $D Q B 1 * 0602$ chromosome from either an affected or unaffected parent, suggesting that the genetic origin of the $D Q B 1 * 0602$ chromosome is independent of affected status (Mignot 1997). This, together with the finding that rare non-DR15 narcoleptic patients often carry complex recombinant haplotypes sharing only $D Q A 1 * 0102$ and $D Q B 1 * 0602$ (Mignot et al. 1997), rather suggests a primary role for $H L A$-DQ in disease susceptibility. As $D Q B 1 * 0602$ is found in $20 \%-25 \%$ of the Caucasian North American population (Begouich et al. 1992; Fernandez-Vina et al. 1991), other factors must also be involved.

The fact that genomic sequencing in the $D Q$ region did not reveal evidence for other candidate genes also argues in favor of a primary role for HLA-DQ. There has been much speculation about a possible role for the HLA class II system in the etiology of the disease (Carlander et al. 1993; Mignot et al. 1995b; Parkes et al. 1986), but positive evidence in support of an immune involvement remains elusive at this time. One possibility is that these particular $H L A$ alleles are involved in positive selection of a subset of $\mathrm{T}$ cells in response to a particular environmental stimulus which then leads to tissue destruction and subsequent pathology leading to disease. Even if most studies to date have found no evidence for an autoimmune process in narcolepsy (Carlander et al. 1993; Fredrikson et al. 1990; Mignot et al. 1995b; Rubin et al. 1988), recent results have shown increased microglial HLA class II expression in the white matter and neuronal degeneration in the amygdala and the basal forebrain of narcoleptic canines (Siegel et al. 1995; Tafti et al. 1996). The population genetic characteristics of narcolepsy are similar to several diseases of known autoimmune etiology such as insulin-dependent diabetes mellitus and multiple sclerosis, and include low relative risk values for HLA susceptibility alleles (Billiard et al. 1994; Guilleminault et al. 1989; Honda and Matsuki 1990; Kales et al. 1982; Mignot 1997), and a low rate of concordance in twins (Mignot 1997; Partinen et al. 1994).

Our results also suggest that the sequence variation associated with $D Q B 1 * 0602$ and narcolepsy is phylogenetically ancient. The four-marker $D Q B 1 * 0602$ haplotype was observed in both Caucasians and a small number of
Blacks. Although $(\mathrm{CA})_{\mathrm{n}}$ repeats are thought to mutate at a faster rate than gene sequences, the microsatellite alleles associated with the $D Q B 1 * 0602$ haplotype have been preserved in both populations, and thus variation at this level appears to predate the divergence of the races. Although the mechanisms that work to preserve this sequence variation are unclear, recent work suggests that microsatellites containing smaller numbers of $(\mathrm{CA})_{\mathrm{n}}$ repeats are less susceptible to change than are longer repeats (Jin et al. 1996). The microsatellite alleles observed on the $D Q B 1 * 0602$ haplotype are among the shorter alleles for those particular markers, and thus may be more likely to be preserved over long periods of time. It would be of interest to determine the arrangement and allelic associations of these markers in other ethnic groups as well as other primate species.

Acknowledgments We thank D. Chaplin and D. Le Paslier for YAC clones, R. Wolff for advice on cell fusions, A. Gnirke for advice on RARE cleavage mapping, J. Yu for the sCos-dRI vector, E. Morikang for random DNA samples, and D. Hadley for transposon mapping. We also thank R. Myers, D. Cox, and E. Sigal for helpful advice and discussions, and the staff of Mercator Genetics, Inc. for critical comments on the manuscript.

\section{References}

Abderrahim, H., Sambucy, J.-L., Iris, F., Ougen, P., Billault, A., Chumakov, I. M., Dausset, J., Cohen, D., and Le Paslier, D. Cloning the human major histocompatibility complex in YACs. Genomics 23: 520-527, 1994

Aldrich, M. S. The neurobiology of narcolepsy-cataplexy. Prog Neurobiol 41: 533-541, 1993

Aldrich, M. S., Prokopowicz, G., Ockert, K., Hollingsworth, Z., Penney, J. B., and Albin, R. L. Neurochemical studies of human narcolepsy: alpha-adrenergic receptor autoradiography of human narcoleptic brain and brainstem. Sleep 17: 598-608, 1994

Altschul, S. F., Gish, W., Miller, W., Myers, E. W., and Lipman, D. J. Basic local alignment search tool. J Mol Biol 215: 403-410, 1990 Andreas-Zietz, A., Keller, E., Roth, B., Nevsimalova, S., Sonka, K., Docekal, P., Ivaskova, E., Kupkova, L., Sadjlova, H., Schulz, H., Geisler, P., Scholz, S., and Albert, E. The Occurence of HLA DR2 in 118 Narcoleptics, Fifth International Congress of Sleep Research, Copenhagen, Denmark, 1987

Beckmann, J. S. and Weber, J. L. Survey of human and rat microsatellites. Genomics 12: 627-631, 1992

Begovich, A. B., McClure, G. R., Suraj, V. C., Helmuth, R. C., Fildes, N., Bugawan, T. L., Erlich, H. A., and Klitz, W. Polymorphism, recombination, and linkage disequilibrium within the $H L A$ class II region. J Immunol 148: 249-58, 1992

Billiard, M., Seignalet, J., Besset, A., and Cadilhac, J. HLA-DR2 and narcolepsy. Sleep 9: 149-52, 1986

Billiard, M., Pasquie-Magnetto, V., Heckman, M., Carlander, B., Besset, A., Zachariev, Z., Eliaou, J. F., and Malafosse, A. Family studies in narcolepsy. Sleep 17: S54-S59, 1994

Carlander, B., Eliaou, J. F., and Billiard, M. Autoimmune hypothesis in narcolepsy. Neurophysiol Clin 23: 15-22, 1993

Chu, G., Vollrath, D., and Davis, R. W. Separation of large DNA molecules by contour-clamped homogeneous electric fields. Science 234: 1582-1585, 1986

Erlich, S. S. and Itabashi, H. H. Narcolepsy: a neuropathologic study. Sleep 9: 126-132, 1986 
Fernandez-Vina, M. A., Gao, X. J., Moraes, M. E., Moraes, J. R., Salatiel, I., Miller, S., Tsai, J., Sun, Y. P., An, J. B., Layrisse, Z., Gazit, E., Brautbar, C., and Stastny, P. Alleles at four HLA class II loci determined by oligonucleotide hybridization and their associations in five ethnic groups. Immunogenetics 34: 299-312, 1991

Ferrin, L. J. and Camerini-Otero, R. D. Selective cleavage of human DNA: recA-assisted restriction endonuclease (RARE) cleavage. Science 254: 1494-1497, 1991

Fredrikson, S., Carlander, B., Billiard, M., and Link, H. CSF immune variables in patients with narcolepsy. Acta Neurol Scand 81: 253254, 1990

Gillett, W., Hanks, L., Ka-Shung Wong, G., Yu, J., Lim, R., and Olson, M. V. Assembly of high-resolution restriction maps based on multiple complete digests of a redundant set of overlapping clones. Genomics 33: 389-408, 1996

Gnirke, A., Iadonato, S. P., Kwok, P.-Y., and Olson, M. V. Physical calibration of yeast artificial chromosome contig maps by recAassisted restriction endonuclase (RARE) cleavage. Genomics 24: 199-210, 1994

Guilleminault, C., Mignot, E., and Grumet, F. C. Familial patterns of narcolepsy. Lancet 2: 1376-1379, 1989

Hillier, L. and Green, P. OSP: a computer program for choosing PCR and DNA sequencing primers. PCR Methods Appl 1: 124-8, 1991

Honda, Y. and Matsuki, K. Genetic aspects of narcolepsy. In M. Thorpy (ed.): Handbook of Sleep Disorders, pp. 217-234, Marcel Dekker, Inc., New York, 1990

Hudson, T., Stein, L., Gerety, S., Ma, J., Castle, A., Silva, J., Slonim, D., Baptista, R., Kruglyak, L., Xu, S., Hu, X., Colbert, A., Rosenberg, C., Reeve-Daly, M., Rozen, S., Hui, L., Wu, X., Vestergaard, C., Wilson, K., Bae, J., Maitra, S., Ganiatsas, S., Evans, C., DeAngelis, M., Ingalls, K., Nahf, R., Horton, L., Oskin, M., Collymore, A., Ye, W., Kouyoumjian, V., Zernsteva, I., Tarn, J., Devine, R., Courtney, D., Renaud, M., Nguyen, H., O’Connor, T., Fizames, C., Faure, S., Gyapay, G., Dib, C., Morissette, J., Orlin, J., Birren, B., Goodman, N., Weissenbach, J., Hawkins, T., Foote, S., Page, D., and Lander, E. An STS-based map of the human genome. Science 270: 1945-1954, 1995

Iadonato, S. P. and Gnirke, A. RARE-cleavage analysis of YACs. In D. Markie (ed.): Yeast Artificial Chromosome Protocols, pp. 75-85, Humana Press, Totowa, New Jersey, 1994

Jackson, C. L. Somatic cell hybrids. In N. C. Dracopoli, J. L. Haines, B. R. Korf, D. T. Moir, C. C. Morton, C. E. Seidman, J. G. Seidman, and D. R. Smith (eds.): Current Protocols in Human Genetics, J. Wiley and Sons, New York, 1994

Jin, L., Macaubas, C., Hallmayer, J., Kimura, A., and Mignot, E. Mutation rate varies among alleles at a microsatellite locus: phylogenetic evidence. Proc Natl Acad Sci USA 93: 1528515288, 1996

Juji, T., Satake, M., Honda, Y., and Doi, Y. HLA antigens in Japanese patients with narcolepsy. All the patients were DR2 positive. Tissue Antigens 24: 316-319, 1984

Kales, A., Cadieux, R. J., Soldatos, C. R., Bixler, E. O., Schweitzer, P. K., Prey, W. T., and Vela-Bueno, A. Narcolepsy-cataplexy. I. Clinical and electrophysiologic characteristics. Arch Neurol 39: 164-168, 1982

Kozono, H., Bronson, S. K., Taillon-Miller, P., Moorti, M. K., Jamry, I., and Chaplin, D. D. Molecular linkage of the HLA-DR, HLA-DQ, and $H L A-\mathrm{DO}$ genes in yeast artificial chromosomes. Genomics 11: 577-86, 1991

Lin, L., Kuwata, S., Tokunaga, K., Sasaki, T., Honda, Y., and Juji, T. Analysis of HLA class II genes by single-strand confirmation polymorphisms in narcolepsy. In K. Tsuji, M. Aizawa, and T. Sasasuki (eds.): HLA 1991: Proceedings of the Eleventh International Histocompatibility Workshop and Conference, pp. 333-335, Oxford University Press, New York, 1992

Litt, M. and Browne, D. Characterization of (CA)n Microsatellite Repeats from Large-Insert Clones. In N. C. Dracopoli, J. L. Haines, B. R. Korf, D. T. Moir, C. C. Morton, C. E. Seidman, J. G. Seidman, and D. R. Smith (eds.): Current Protocols in Human Genetics, J. Wiley and Sons, New York, 1994
Lock, C. B., So, A. K., Welsh, K. I., Parkes, J. D., and Trowsdale, J. MHC class II sequences of an HLA-DR2 narcoleptic. Immunogenetics 27: 449-55, 1988

Macaubas, C., Hallmayer, J., Kalil, J., Kimura, A., Yasunaga, S., Grumet, F. C., and Mignot, E. Extensive polymorphism of a (CA)n microsatellite located in the HLA- DQA1/DQB1 class II region. Hum Immunol 42: 209-220, 1995

Mignot, E., Lin, X., Arrigoni, J., Macaubas, C., Olive, F., Hallmayer, J., Underhill, P., Guilleminault, C., Dement, W. C., and Grumet, F. C. DQB1*0602 and DQA1*0102 (DQ1) are better markers than DR2 for narcolepsy in Caucasian and Black Americans. Sleep 17: S60S67, 1994

Mignot, E., Kimura, A., Abbal, M., Thorsby, E., Lin, X., Voros, A., Macaubas, C., Bouissou, F., Sollid, L. M., Cambon-Thomsen, A., and et al. DQCAR microsatellite polymorphisms in three selected HLA class II- associated diseases. Tissue Antigens 46: 299-304, $1995 \mathrm{a}$

Mignot, E., Tafti, M., Dement, W. C., and Grumet, F. C. Narcolepsy and immunity. Adv Neuroimmunol 5: 23-37, 1995b

Mignot, E., Kimura, A., Latterman, A., Lin, X., Yasunaga, S., MuellerEckardt, G., Rattazzi, C., Lin, L., Guilleminault, C., Grumet, F. C., Mayer, G., Dement, W. C., and Underhill, P. Extensive HLA class II studies in 58 non DRB1*15 (DR2) narcoleptic patients with cataplexy. Tissue Antigens 49: 329-341, 1997

Mignot, E. Genetic and familial aspects of narcolepsy. Neurology, in press

Mueller-Eckhardt, G., Meier-Ewert, K., Schendel, D. J., Reinecker, F. B., Multhoff, G., and Mueller-Eckhardt, C. HLA and narcolepsy in a German population. Tissue Antigens 28: 163-169, 1986

Myers, R. M., Sheffield, V. C., and Cox, D. R. Detection of single base changes in DNA: ribonuclease cleavage and denaturing gradient gel electrophoresis. In K. Davies (ed.): Genome Analysis: A Practical Approach, pp. 95-139, IRL Press, Oxford, 1988

Neely, S. E., Rosenberg, R. S., Spire, J. P., Antel, J., and Arnason, W. Familial narcolepsy and HLA antigens. Ann Neurol 20: 168, 1986

Neely, S., Rosenberg, R., Spire, J. P., Antel, J., and Arnason, B. G. HLA antigens in narcolepsy. Neurology 37: 1858-1860, 1987

Nishino, S. and Mignot, E. Pharmacological aspects of human and canine narcolepsy. Prog Neurobiol 52: 27-78, 1997

Olerup, O. and Zetterquist, H. HLA-DR typing by PCR amplification with sequence-specific primers (PCR- SSP) in 2 hours: an alternative to serological DR typing in clinical practice including donorrecipient matching in cadaveric transplantation. Tissue Antigens 39: 225-235, 1992

Olerup, O., Aldener, A., and Fogdell, A. HLA-DQB1 and -DQA1 typing by PCR amplification with sequence-specific primers (PCRSSP) in 2 hours. Tissue Antigens 41: 119-34, 1993

Parkes, J. D., Langdon, N., and Lock, C. Narcolepsy and immunity. $\mathrm{Br}$ Med J (Clin Res Ed) 292: 359-360, 1986

Partinen, M., Hublin, C., Kaprio, J., Koskenvuo, M., and Guilleminault, C. Twin studies in narcolepsy. Sleep 17: S13-S16, 1994

Poirier, G., Montplaisir, J., Decary, F., Momege, D., and Lebrun, A. $H L A$ antigens in narcolepsy and idiopathic central nervous system hypersomnolence. Sleep 9: 153-158, 1986

Rogers, A. E., Mehan, J., Guilleminault, C., Grumet, F. C., and Mignot, E. HLA DR15 (DR2) and DQB1*0602 typing studies in 188 narcoleptic patients with cataplexy. Neurology 48: 1550-1556, 1997

Rubin, R. L., Hajdukovich, R. M., and Mitler, M. M. HLA-DR2 association with excessive somnolence in narcolepsy does not generalize to sleep apnea and is not accompanied by systemic autoimmune abnormalities. Clin Immunol Immunopathol 49: 149158,1988

Ruddy, D. A., Lee, V. K., Kronmal, G. S., Mintier, G. A., Quintana, L., Domingo, R., Meyer, N. C., Basava, A., McClelland, E., Fullan, A., Mapa, F. A., Moore, T., Thomas, W., Loeb, D. B., Harmon, C., Tsuchihashi, Z., Wolff, R. K., Schatzman, R. C., and Feder, J. N. A 1.1 megabase transcript map of the hereditary hemochromatosis locus. Genome Res 7: 441-456, 1997

Scharf, S. J., Horn, G. T., and Erlich, H. A. Direct cloning and sequence analysis of enzymatically amplified genomic sequences. Science 233: 1076-1078, 1986 
Siegel, J. M., Fahringer, H. M., Anderson, L., Nienhuis, R., Gulyani, S., Massiri, J., Mignot, E., and Switzer, R. C. Evidence of localized neuronal degeneration in narcolepsy: studies in the narcoleptic dog. Sleep Research 24: 354, 1995

Tafti, M., Nishino, S., Aldrich, M. S., Liao, W., Dement, W. C., and Mignot, E. Major histocompatibility class II molecules in the CNS: increased microglial expression at the onset of narcolepsy in canine model. J Neurosci 16: 4588-4595, 1996

Uberbacher, E. C., Xu, Y., and Mural, R. J. Discovering and understanding genes in human DNA sequence using GRAIL. Meth Enzymol 266: 259-281, 1996

Uryu, N., Maeda, M., Nagata, Y., Matsuki, K., Juji, T., Honda, Y., Kawai, J., Ando, A., Tsuji, K., and Inoko, H. No difference in the nucleotide sequence of the DQ beta beta 1 domain between narcoleptic and healthy individuals with DR2,Dw2. Hum Immunol 24: $175-81,1989$
Weber, J. L. Informativeness of human (dC-dA)n.(dG-dT)n polymorphisms. Genomics 7: 524-30, 1990

Weber, J. L. and May, P. E. Abundant class of human DNA polymorphisms which can be typed using the polymerase chain reaction. Am J Hum Genet 44: 388-396, 1989

Wolff, R. K., Frazer, K. A., Jackler, R. K., Lanser, M. J., Pitts, L. H., and Cox, D. R. Analysis of chromosome 22 deletions in neurofibromatosis type 2-related tumors. Am J Hum Genet 51: 478-485, 1992

Yasunaga, S., Kimura, A., Hamaguchi, K., Ronningen, K. S., and Sasazuki, T. Different contribution of $H L A-D R$ and -DQ genes in susceptibility and resistance to insulin-dependent diabetes mellitus (IDDM). Tissue Antigens 47: 37-48, 1996 